\title{
CARACTERIZACIÓN CULTURAL-MORFOMÉTRICA COMO HERRAMIENTA PARA LA IDENTIFICACIÓN DE Fusarium SPP., ASOCIADO A Nicotiana tabacum L.
}

\author{
Oandis Sosa-Sánchez ${ }^{1}$, Mirella Romero-Bastidas², Juan José Silva-Pupo ${ }^{3}$, Ramiro Remigio Gaibor- \\ Fernández ${ }^{4}$, Sergio Florentino Rodríguez-Rodríguez ${ }^{5}$, Wilson Geobel Ceiro-Catasút ${ }^{6 / *}$ \\ Palabras clave: Especies fúngicas; pudrición basal del tallo; tabaco; taxonomía. \\ Keywords: Fungal species; basal stem rot; tobacco; taxonomy.
}

Recibido: $14 / 12 / 2020$

Aceptado: 25/03/2021

RESUMEN

Introducción. Nicotiana tabacum L., es un cultivo de importancia económica como producto exportable en Cuba y sus plantaciones pueden ser afectadas significativamente por el fitopatógeno Fusarium spp. Objetivo. El objetivo fue caracterizar cultural y morfométricamente las especies de Fusarium asociadas a $N$. tabacum. Materiales y métodos. Se colectaron muestras de plantas con afectaciones vasculares, marchitamiento, clorosis y necrosis en tallos y hojas en áreas especializadas en la producción tabacalera en la provincia cubana de Granma. A partir de los tejidos vegetales analizados se obtuvieron 9 aislados en medio Papa Dextrosa Agar (PDA), que se purificaron con cultivos monospóricos. Se utilizaron lo medios PDA, Carnation Leafpiece Agar (CLA), Spezieller Nährstoffarmer Agar (SNA) y Agar Nutriente (AN) para la

* Autor para correspondencia. Correo electrónico: wceiroc@udg.co.cu

1 Universidad de Granma, Departamento Agronomía, Facultad de Ciencias Agropecuarias, Bayamo, Granma, Cuba.

\section{(iD) 0000-0002-8231-3822.}

2 Universidad Autónoma de Baja California Sur, Departamento Académico de Agronomía, La Paz, B.C.S., México. (D) 0000-0002-1579-0194.

3 Universidad de Granma, Departamento Agronomía, Facultad de Ciencias Agropecuarias, Bayamo, Granma, Cuba.

(D) 0000-0003-1049-5740.

\section{ABSTRACT}

Cultural-morphometriccharacterization as a tool for the identification of Fusarium spp., associated with Nicotiana tabacum L. Introduction. Nicotiana tabacum L., is a crop of economic importance as an exportable product in Cuba and its plantations can be significantly affected by the phytopathogen Fusarium spp. Objective. The objective was to characterize culturally and morphometrically the Fusarium species associated with $N$. tabacum. Materials and methods. Samples of plants with vascular affectations, wilting, chlorosis and necrosis in stems and leaves were collected in areas specialized in tobacco production in the Cuban province of Granma. From the analyzed plant tissues, 9 isolates were obtained in Potato Dextrose Agar (PDA) medium, which were purified by monosporic cultures. PDA,

4 Universidad Técnica Estatal de Quevedo, Agronomía, Los Ríos, Ecuador.

(D) 0000-0002-0981-2000.

5 Universidad de Granma, Departamento Agronomía, Facultad de Ciencias Agropecuarias, Bayamo, Granma, Cuba.

(iD) 0000-0003-2923-5092.

6 Universidad de Granma, Departamento Agronomía, Facultad de Ciencias Agropecuarias, Bayamo, Granma, Cuba.

(D) 0000-0003-2065-2279. 
caracterización cultural-morfométrica sobre la base de caracteres cualitativos y cuantitativos. Se utilizó un diseño completamente aleatorizado y el procesamiento estadístico se realizó mediante un ANOVA factorial y la prueba de Tukey, procesado con InfoStat 2008. Resultados. Los resultados confirmaron la existencia de 9 aislados de Fusarium, de ellos, 5 de F. oxysporum y 4 de $F$. phyllophylum. La caracterización combinada cultural-morfométrica demostró una mayor variabilidad de la pigmentación en medio PDA en ambas especies de Fusarium y evidenció diferenciación inter e intraespecífica en la formación de estructuras microscópicas, constatándose macroconidios con una talla de $8,17-33,35$ x 1,45-6,30 $\mu \mathrm{m}$ en $F$. oxysporum y de 6,68-20,10 x 1,42-4,67 $\mu \mathrm{m}$ en $F$. phyllophylum.

Conclusiones. Se caracterizan eficazmente por el método combinado cultural-morfométrico 9 aislados de Fusarium spp., (5 de F. oxysporum y 4 de $F$. phyllophylum) y se pone de manifiesto la selectividad de estas 2 especies por $N$. tabacum.

\section{INTRODUCCIÓN}

El tabaco (Nicotiana tabacum L.) es una de las plantas comerciales no comestibles que ocupa mayor área de siembra en la agricultura mundial y es uno de los pocos cultivos agroindustriales que se comercializa completamente en forma de hojas (Calero-Hurtado et al. 2019). En Cuba la producción de $N$. tabacum se realiza principalmente al sol y empalado, del cual se obtiene el puro cubano que posee una excelente calidad y un alto costo en el mercado internacional (Toledo et al. 2016).

En Cuba se plantan anualmente aproximadamente 15868 ha, con un rendimiento promedio de 3,89 t.ha ${ }^{-1}$, mientras que, en la provincia Granma solamente se obtienen 1,0 t.ha ${ }^{-1}$. Este
Carnation Leafpiece Agar (CLA), Spezieller Nährstoffarmer Agar (SNA) and Nutrient Agar (AN) media were used for cultural-morphometric characterization on the basis of qualitative and quantitative traits. A completely randomized design was used and statistical processing was performed using factorial ANOVA and Tukey's test, processed with InfoStat 2008. Results. The results confirmed the existence of 9 isolates of Fusarium, of them, 5 of $F$. oxysporum and 4 of $F$. phyllophylum. The combined culturalmorphometric characterization demonstrated greater variability of pigmentation in PDA medium in both Fusarium species and evidenced inter and intraspecific differentiation in the formation of microscopic structures, verifying macroconidia with a size of 8.17-33.35 x 1.45$6.30 \mu \mathrm{m}$ in $F$. oxysporum and $6.68-20.10 \times 1.42-$ $4.67 \mu \mathrm{m}$ in $F$. phyllophylum. Conclusions. Nine Fusarium spp. Isolates (5 from $F$. oxysporum and 4 from $F$. phyllophylum) are efficiently characterized by the combined culturalmorphometric method and the selectivity of these 2 species for $N$. tabacum is demonstrated.

bajo rendimiento puede ser atribuido a las afectaciones del fitopatógeno Fusarium spp. (Barceló y Mustelier 2019). Esta especie fúngica se conoce mundialmente por causar la enfermedad denominada marchitez vascular y es capaz de ocasionar la pudrición basal del tallo en tabaco. Tanto en semilleros como en campo abierto, causa daños en el sistema radical, que afecta directamente los procesos de absorción de agua y nutrientes e influye negativamente sobre el rendimiento y calidad del cultivo (Retana et al. 2018).

La identificación de Fusarium spp., es compleja y requiere de mucho tiempo, recursos humanos y materiales. La caracterización cultural posibilita el desarrollo de microorganismos en un medio de cultivo in vitro y con ello, los aspectos cualitativos relacionados con la forma, 
tamaño, textura, coloración, esporulación, entre otros, mientras que la morfométrica permite dilucidar las estructuras de interés taxonómico para determinar elementos relacionados con su talla. Por tanto, la combinación de estas formas de caracterización propone una efectiva identificación de especies fúngicas con claves ilustradas, sin recurrir a las técnicas moleculares que requieren mayor cantidad de recursos materiales y financieros, inaccesibles para muchos países pobres y en vías de desarrollo (Leslie y Summerell 2008, Castro López et al. 2018).

Conocer las principales características de las especies de Fusarium que afectan a $N$. tabacum en agroecosistemas tabacaleros de la provincia Granma, resultará de gran interés científico para los programas de mejora de esta planta y para el establecimiento de alternativas de manejo del fitopatógeno en etapa de semillero y en campo. Según lo anterior, el objetivo de esta investigación fue caracterizar cultural-morfométricamente las especies de Fusarium asociadas a $N$. tabacum cultivado en la provincia Granma, Cuba.

\section{MATERIALES Y MÉTODOS}

Muestreo. Se muestrearon áreas especializadas en la producción de $N$. tabacum a campo abierto en la provincia Granma (Tabla 1). Las plantaciones tenían edades entre 20-40 días después del trasplante. Los campos se muestrearon en forma diagonal, se colectaron plantas enteras con daños evidentes de pudrición basal del tallo, con síntomas de clorosis y marchitez del follaje (González et al. 2005). Las muestras obtenidas se introdujeron en bolsas de nylon y se trasladaron inmediatamente al Centro de Estudios de Biotecnología Vegetal (CEBVEG), Facultad de Ciencias Agropecuarias, Universidad de Granma, Cuba, para su procesamiento y caracterización.

Tabla 1. Lugar de procedencia de las muestras. Cuba.

\begin{tabular}{lccc}
\hline \multirow{2}{*}{ Municipio } & Localidad & Coordenadas \\
\cline { 3 - 4 } & & Norte & Oeste \\
\hline Buey Arriba & Bueycito & $20^{\circ} 14^{\prime} 20.5$ & $76^{\circ} 46^{\prime} 28.8$ \\
Guisa & Corojito & $20^{\circ} 11^{\prime} 05.2$ & $76^{\circ} 43^{\prime} 21.7$ \\
Bayamo & Monjará & $20^{\circ} 17^{\prime} 51.9$ & $76^{\circ} 36^{\prime} 08.7$ \\
Jiguaní & El Dorado & $20^{\circ} 15^{\prime} 52.3$ & $76^{\circ} 44^{\prime} 43.8$ \\
Yara & Santa Rita & $20^{\circ} 20^{\prime} 11.9$ & $76^{\circ} 29^{\prime} 24.1$ \\
\hline
\end{tabular}

Procesamiento en laboratorio. Cada muestra se cortó en fragmentos de $1 \mathrm{~cm}$ y se desinfestó con hipoclorito de sodio $(\mathrm{NaClO})$ al 1,0\% durante 3 minutos; luego se lavaron con detergente comercial y finalmente se enjuagaron 3 veces con agua destilada esterilizada.
Seguidamente se establecieron cámaras húmedas en placas Petri $(\varnothing=90 \mathrm{~mm})$ con papel de filtro esterilizado y humedecido. Se incubaron a $28 \pm 2^{\circ} \mathrm{C}$ y se observaron diariamente hasta la aparición de estructuras fúngicas durante $168 \mathrm{~h}$. Luego se verificó la presencia de Fusarium spp., 
al microscopio óptico (Novel, modelo N200M, China) y con ayuda de un asa de siembra se recogieron fragmentos de micelio que fueron sembrados en placas Petri $(\varnothing=90 \mathrm{~mm})$ en medio PDA: 39 g. $\mathrm{L}^{-1}$ BioCen, esterilizado a $121^{\circ} \mathrm{C}$ durante 15 min y $\mathrm{pH}=6)$ más cloranfenicol $\left(0,01\right.$ g. $\left.\mathrm{L}^{-1}\right)$, incubándose a $28 \pm 2^{\circ} \mathrm{C}$ en oscuridad hasta lograr el crecimiento de las colonias.

Las colonias crecidas en las placas se cubrieron con $10 \mathrm{~mL}$ de agua destilada estéril y se homogenizaron en un agitador Vortex por $30 \mathrm{~s}$. Con un asa bacteriológica desinfectada, se tomó una asada de la suspensión y se depositó en el centro de las placas $(\varnothing=90 \mathrm{~mm})$ que contenía $5 \mathrm{~mL}$ de medio de cultivo Agar agua (2\%) para dispersarla con una varilla $\mathrm{L}$ de vidrio. Todas las placas se sellaron con parafilm y se incubaron a $28 \pm 2^{\circ} \mathrm{C}$ y oscuridad durante $24 \mathrm{~h}$. Luego, bajo microscopio óptico (20x) se detectaron y señalaron conidios solitarios germinados. Seguidamente con una aguja de siembra flameada se transfirió el fragmento de agar que contenía el conidio germinado a una placa Petri con medio de cultivo PDA más cloranfenicol. Las placas se sellaron con parafilm e incubaron a $28 \pm 2^{\circ} \mathrm{C}$ durante 7 días. Una vez que se lograron los cultivos puros monospóricos se conservaron a $4^{\circ} \mathrm{C}$. Posteriormente, se comprobaron los postulados de Koch (Duarte et al. 2016).

\section{Caracterización cultural-morfométrica} de aislados de Fusarium spp. Se realizó sobre la base de caracteres cualitativos y cuantitativos, expresados por los aislados sobre los medios de cultivo PDA, Carnation Leafpiece Agar (CLA se elaboró al verter en cada placa $15 \mathrm{ml}$ de Agar agua estéril; seguidamente se depositaron 7 fragmentos de hojas de clavel (Dianthus caryophyllus L) de 3-5 $\mathrm{mm}^{2}$ previamente esterilizadas y $\mathrm{pH}$ ajustado a 6), Spezieller Nährstoffarmer Agar (SNA: $1 \mathrm{~g}$ de $\mathrm{KH}_{2} \mathrm{PO}_{4}$, $1 \mathrm{~g}$ de $\mathrm{KNO}_{3}, 0,5$ de $\mathrm{MgSO}_{4} \cdot 7 \mathrm{H}_{2} \mathrm{O}, 0,5 \mathrm{de} \mathrm{KCl}, 0,2$ de glucosa, 0,2 de sacarosa, $20 \mathrm{~g}$ de Agar, esterilizado a $121^{\circ} \mathrm{C}$ durante 15 min y $\mathrm{pH}$ ajustado a 6) y agar nutriente (AN: 28 g.L.-1 BioCen, esterilizado a $121^{\circ} \mathrm{C}$ durante 15 min y pH ajustado a 6). Se emplearon placas Petri $(\varnothing=90 \mathrm{~mm})$ que contenían $20 \mathrm{~mL}$ de cada medio de cultivo independientemente. Las mismas se inocularon, central e individualmente, con un disco de micelio $(\varnothing=5 \mathrm{~mm})$ de cada aislado, proveniente de la periferia de colonias crecidas sobre PDA durante 7 días. Las placas, 4 por aislado (réplicas), se sellaron con parafilm e incubaron $\left(28 \pm 2^{\circ} \mathrm{C}\right.$ y oscuridad). Las evaluaciones se realizaron cada $24 \mathrm{~h}$ hasta las 168 h. La coloración de la colonia en el anverso y reverso se determinó por observación visual y se documentó mediante fotografías con una cámara digital. También se describió la textura superficial, forma de los bordes, presencia de anillos en el anverso, formación de sectores y concentración de esporas. Se midió el diámetro de la colonia con una métrica graduada. A partir del diámetro de la colonia se calculó la velocidad media de crecimiento al séptimo día de incubación, mediante el empleo de la siguiente fórmula:

\section{$\mathrm{V}$ crec $=\mathrm{DC} / \mathrm{T}$}

Donde

$$
\begin{aligned}
\mathrm{V} \text { crec }= & \text { velocidad de crecimiento del aislado } \\
& \left(\mathrm{mm}^{-1} \mathrm{~h}^{-1}\right) \\
\mathrm{DC}= & \text { diámetro de las colonias }(\mathrm{mm}) \\
\mathrm{T}= & \text { tiempo transcurrido }(\mathrm{h})
\end{aligned}
$$

El conteo de las esporas se realizó a los 7 días del crecimiento de las colonias de cada aislado y en cada medio. A las placas con los aislados crecidos se le adicionó $10 \mathrm{mI}$ de agua destilada estéril y se homogeneizaron con una varilla $\mathrm{L}$ de vidrio. La suspensión de esporas se colectó en un tubo de ensayo con una capacidad de $20 \mathrm{mI}$. A partir de estas, se prepararon diluciones hasta $10^{-2}$. Se usó un tubo capilar para extraer pequeñas porciones de la dilución y se depositó una gota en una cámara de Neubauer para determinar la concentración de los macroconidios con ayuda de un microscopio Novel a 40x.

Aspectos taxonómicos evaluados. Se preparó un microcultivo en porta objeto cavado con medio CLA, donde se depositó un fragmento 
de 3-5 $\mathrm{mm}^{2}$ de hoja de clavel esterilizado y sobre este se añadió una gota de medio agar agua (AA: 20 g. $\mathrm{L}^{-1}$ BioCen, esterilizado a $121^{\circ} \mathrm{C}$ durante 15 min y $\mathrm{pH}$ ajustado a 6 ). Una vez solidificado el medio se inoculó cada aislado con ayuda de una aguja de siembra. Seguidamente se estableció el microcultivo en una cámara húmeda. Posteriormente, a las $24 \mathrm{~h}$ se visualizaron al microscopio óptico (40x) los macroconidios, células conidiógenas y microconidios (presencia y disposición). Se hicieron preparaciones microscópicas permanentes para observar la forma, el tamaño de los macroconidios y los septos, y se determinó la presencia y disposición de las clamidosporas. Se observó la pigmentación en todos los medios. En PDA de determinó la forma y la velocidad de crecimiento de las colonias, la formación de esporodoquios y el número de septos en los macroconidios; mientras que, en SNA se observó la presencia de clamidosporas y la forma de los micro y macroconidios. La caracterización hasta nivel de especie se efectuó con la clave taxonómica ilustrada (Leslie y Summerell 2008).

Diseño y procesamiento estadístico. Se utilizó un diseño completamente aleatorizado con arreglo bifactorial: Factor A (4 medios de cultivos) y factor B (9 aislados de Fusarium spp.) para un total de 36 interacciones o tratamientos y 4 réplicas. Se usó un ANOVA bifactorial y la prueba de comparación múltiple de medias de Tukey $(\mathrm{p} \leq 0,05)$. Previamente al ANOVA los valores de concentración de macroconidios fueron transformados por $\mathrm{LOG}(\mathrm{x}+1)$, procesado con el programa estadístico InfoStat 2008.

\section{RESULTADOS}

Caracterización cultural de los aislados de Fusarium spp. Al analizar la pigmentación de los aislados de Fusarium spp., en el anverso de las placas en medio PDA se observó que variaron entre blanco y blanco cremoso, excepto el aislado F que presentó tonalidad violeta. En el reverso la coloración observada fue color crema y blanco. Todos los aislados presentaron colonias con bordes redondeados y regulares, con una textura afelpada y algodonosa. La formación de anillos se evidenció en los aislados $\mathrm{C}$ y G, mientras, que en el aislado $\mathrm{H}$ además de estos caracteres se notaron sectores (Figura 1). 

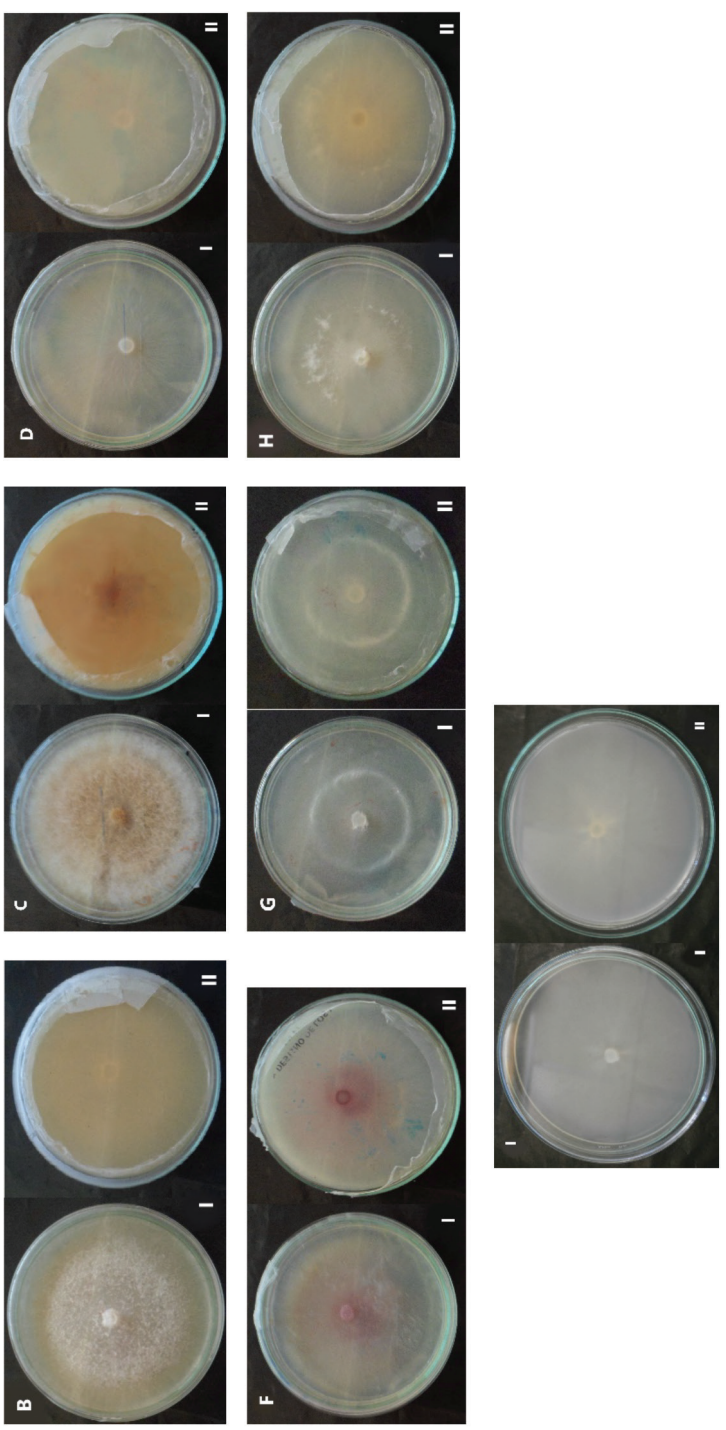

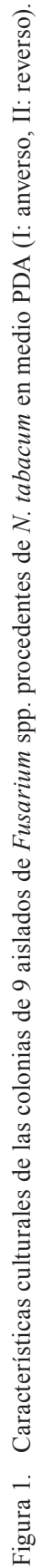
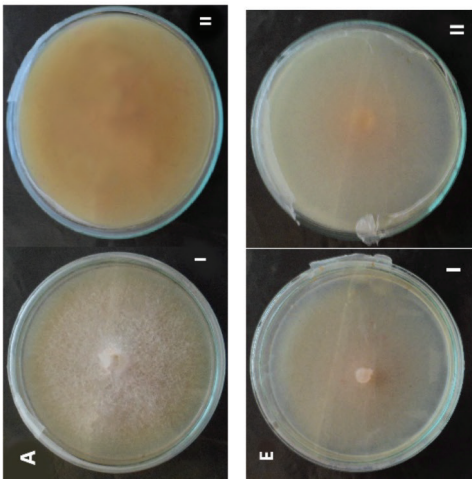

Agronomía Costarricense 46(1): 111-128. ISSN:0377-9424 / 2022 
Por otra parte, en el medio SNA los aislados desarrollaron tonalidades de color blanco, excepto los aislados $\mathrm{C}$ y $\mathrm{F}$ que presentaron color blanco-amarillento. Los bordes fueron redondeados y regulares con una textura algodonosa. La formación de anillos se evidenció en los aislados
B, D y G. En AN y CLA no se observaron variaciones culturales significativas, debido a un crecimiento micelial escaso y poco pigmentado, excepto los aislados B y $\mathrm{F}$ que desarrollaron una textura algodonosa abundante con tonalidad blanca en AN (Figuras 2, 3, 4). 

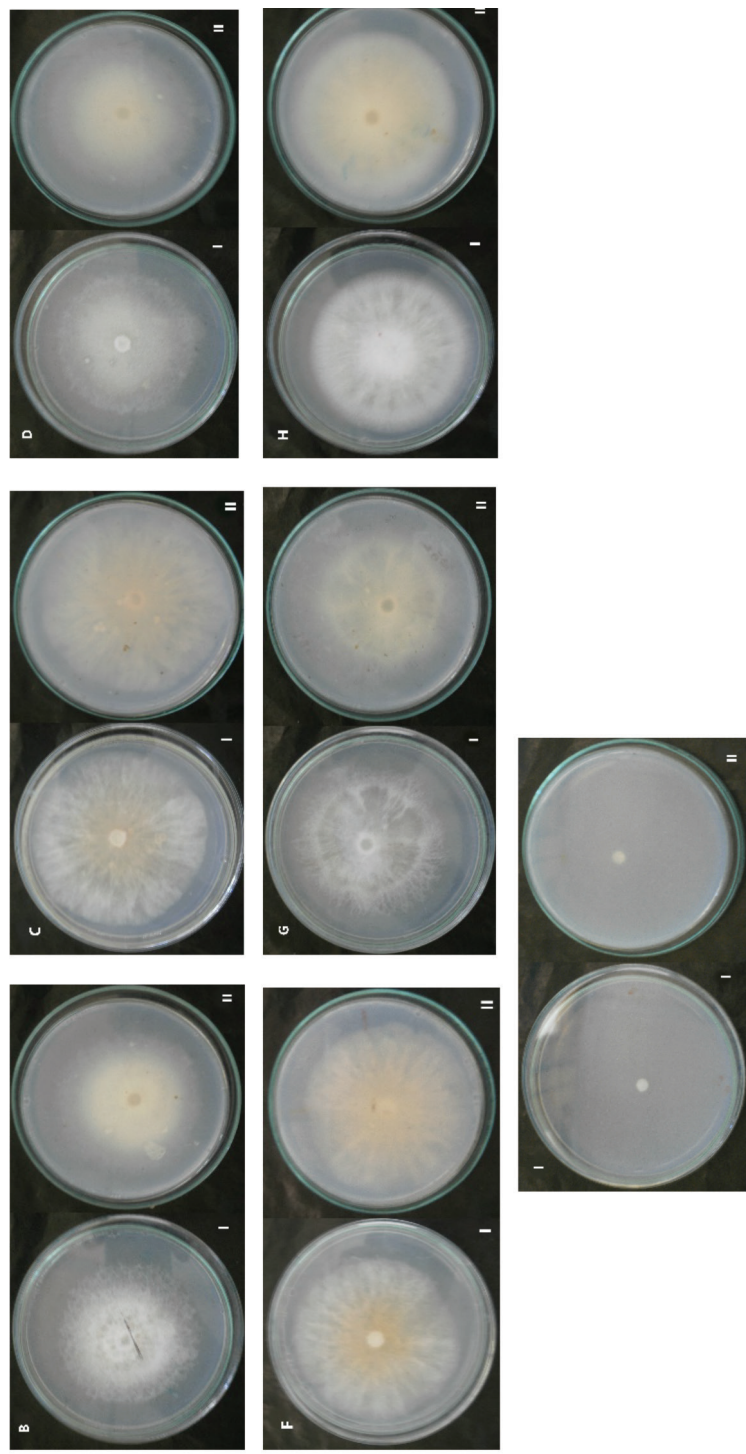

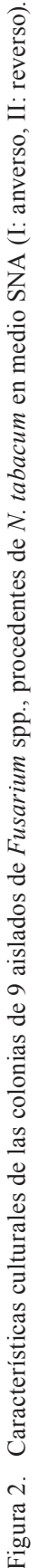

Agronomía Costarricense 46(1): 111-128. ISSN:0377-9424 / 2022 

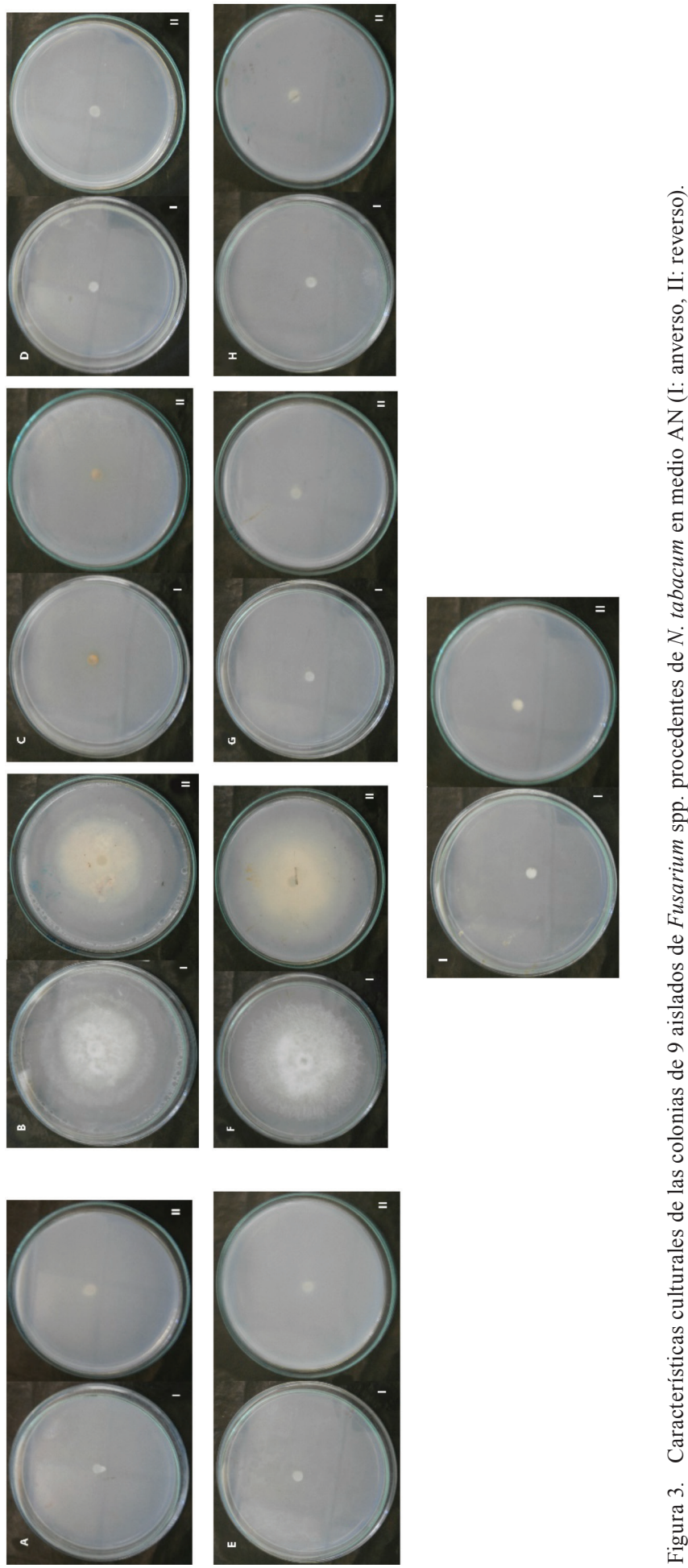

Agronomía Costarricense 46(1): 111-128. ISSN:0377-9424 / 2022 

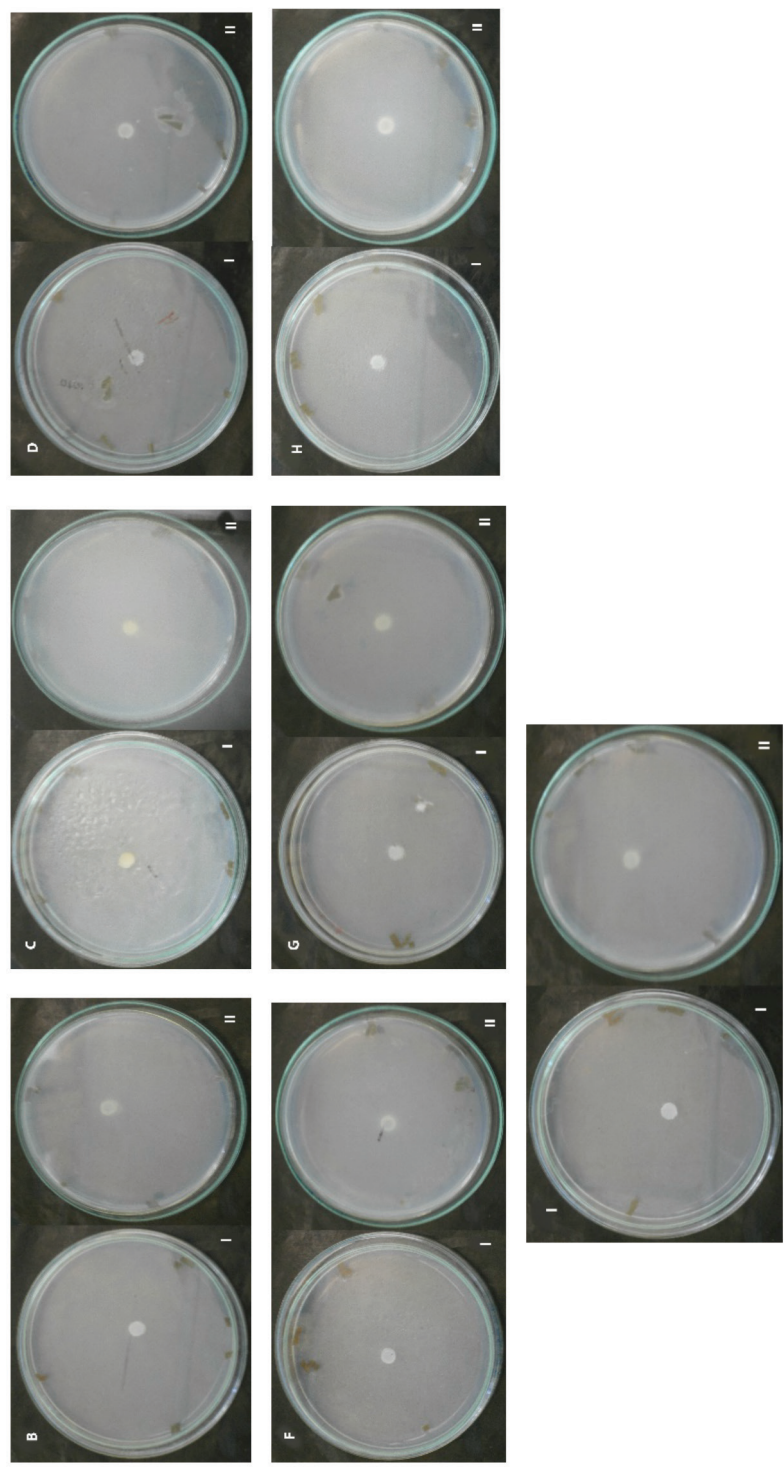

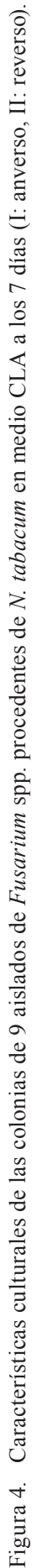

Agronomía Costarricense 46(1): 111-128. ISSN:0377-9424 / 2022 
Finalmente, de esta parte, sobre la base de los resultados alcanzados se consideró al medio PDA como el más idóneo para la caracterización cultural de especies de Fusarium procedentes de $N$. tabacum, debido a una mayor variabilidad cultural y pigmentación.

Caracterización morfométrica de los aislados de Fusarium spp. Al analizar la velocidad media de crecimiento se constataron diferencias (Tukey $\mathrm{p} \leq 0,05$ ) entre aislados en los diferentes medios de cultivo evaluados. La mayor velocidad media se alcanzó en los medios CLA y PDA, mientras que la menor se obtuvo en los medios AN y SNA. Los aislados A, B, $\mathrm{C}$ y $\mathrm{E}$ mostraron una mayor velocidad media en PDA y CLA, respectivamente, así como el aislado $\mathrm{F}$ en $\mathrm{CLA}$, mientras que registraron la menor velocidad media D, G y $\mathrm{H}$ en PDA y $\mathrm{H}$ e I en CLA (Tabla 2).

Tabla 2. Variabilidad de la velocidad media de crecimiento de los aislados de Fusarium spp. provenientes de N. tabacum.

\begin{tabular}{cllll}
\hline \multirow{2}{*}{ Aislados } & \multicolumn{3}{c}{ Velocidad media de crecimiento $\left(\mathrm{mm}^{-h^{-1}}\right)$} \\
\cline { 2 - 4 } & PDA & SNA & CLA & AN \\
\hline A & $0,66 \mathrm{i}$ & 0,53 abcdefgh & 0,60 fghi & 0,52 abcdef \\
B & $0,66 \mathrm{i}$ & 0,53 abcdefgh & 0,60 fghi & 0,52 abcdef \\
C & 0,63 hi & 0,53 abcdefgh & 0,58 defghi & 0,53 abcdefgh \\
D & 0,53 abcdefgh & 0,62 ghi & 0,55 bcdefgh & 0,51 abcdef \\
E & 0,65 i & 0,53 abcdefgh & 0,62 ghi & 0,50 abcde \\
F & 0,55 bcdefgh & 0,62 ghi & 0,60 efghi & 0,50 abcd \\
G & 0,53 abcdefgh & 0,58 cdefghi & 0,55 bcdefgh & 0,53 abcdefgh \\
H & 0,45 a & 0,53 abcdefgh & 0,53 abcdefgh & 0,44 a \\
I & 0,53 abcdefgh & 0,48 abc & 0,53 abcdefg & 0,47 ab \\
ES & & & & \\
\hline
\end{tabular}

Medios de cultivos: PDA =Papa Dextrosa Agar, SNA = Spezieller Nährstoffarmer Agar, CLA = Agar Hojas de clavel, $\mathrm{AN}=$ Agar Nutriente, ES = Error Estándar. Letras distintas en las columnas indican diferencias significativas (Tukey $\mathrm{p} \leq 0,05)$.

Al analizar la concentración de macroconidios se observó diferencias significativas (Tukey $\mathrm{p} \leq 0,05$ ) entre aislados en los diferentes medios de cultivo evaluados. La mayor concentración de macroconidios por aislado se cuantificó en los medios PDA y SNA, y la menor se obtuvo en CLA y AN. Los aislados A, $\mathrm{B}, \mathrm{C}, \mathrm{D}, \mathrm{E}, \mathrm{F}, \mathrm{G}$ e I mostraron mayor esporulación en PDA, mientras que en SNA fueron $\mathrm{B}, \mathrm{C}$, D, E, F y H (Tabla 3). 
Tabla 3. Concentración de macroconidios de los aislados de Fusarium spp. provenientes de N. tabacum.

\begin{tabular}{|c|c|c|c|c|c|c|c|c|}
\hline \multirow{3}{*}{ Aislados } & \multicolumn{8}{|c|}{ Concentración $\left(\mathrm{x} 10^{6}\right.$ macroconidios. $\left.\mathrm{mm}^{-2}\right)$} \\
\hline & \multicolumn{2}{|c|}{ PDA } & \multicolumn{2}{|c|}{ SNA } & \multicolumn{2}{|c|}{ CLA } & \multicolumn{2}{|c|}{$\mathrm{AN}$} \\
\hline & $\bar{X}$ & $\mathrm{Xt}$ & $\bar{X}$ & $\mathrm{Xt}$ & $\bar{X}$ & $\mathrm{Xt}$ & $\bar{X}$ & $\mathrm{Xt}$ \\
\hline A & 0,75 & 5,87 hijk & 0,10 & 4,98 efghij & 0,001 & $3,08 \mathrm{a}$ & 0,002 & $3,23 \mathrm{ab}$ \\
\hline B & 1,03 & $6,01 \mathrm{ijk}$ & 1,60 & $6,20 \mathrm{jk}$ & 0,06 & 4,17 abcde & 0,54 & 5,73 ghijk \\
\hline $\mathrm{C}$ & 0,91 & 5,96 hijk & 2,38 & $6,38 \mathrm{k}$ & 0,01 & 3,96 abcde & 0,01 & 3,79 abcde \\
\hline $\mathrm{D}$ & 1,19 & $6,08 \mathrm{ijk}$ & 0,78 & 5,89 hijk & 0,01 & 4 abcde & 0,01 & 4,00 abcde \\
\hline $\mathrm{E}$ & 0,34 & 5,51 fghijk & 1,17 & $6,07 \mathrm{ijk}$ & 0,06 & 4,54 cdefg & 0,004 & $3,60 \mathrm{abcd}$ \\
\hline $\mathrm{F}$ & 1,19 & $6,08 \mathrm{ijk}$ & 0,89 & 5,55 fgihjk & 0,03 & 4,43 bcdef & 1,10 & $6,04 \mathrm{ijk}$ \\
\hline G & 0,89 & 5,95 hijk & 0,06 & 4,76 defgh & 0,16 & 4,14 abcde & 0,003 & $3,28 \mathrm{abc}$ \\
\hline $\mathrm{H}$ & 0,09 & 4,92 efghi & 0,28 & 5,44 fghijk & 0,28 & 4,08 abcde & 0,01 & 4,11 abcde \\
\hline I & 0,31 & 5,49 fghijk & 0,05 & 3,85 abcde & 0,01 & 3,87 abcde & 0,005 & $3,63 \mathrm{abcd}$ \\
\hline ES & & & & & & & & \\
\hline
\end{tabular}

Medios de cultivos: PDA = Papa Dextrosa Agar, SNA = Spezieller Nährstoffarmer Agar, CLA = Agar Hojas de clavel, $\mathrm{AN}=$ Agar Nutriente, $\mathrm{ES}=$ Error Estándar.

$\bar{X}$ valor promedio, $\mathrm{Xt}=$ valor transformado $\operatorname{LOG}(\mathrm{x}+1)$. Letras distintas en las columnas indican diferencias significativas (Tukey $\mathrm{p} \leq 0,05$ ).

El análisis cultural y morfométrico posibilitó la determinación de 5 especies de $F$. oxysporum (A, B, C, D, H) y 4 de F. phyllophylum (I, E, F, G) (Tabla 4). Todos los aislados de F. oxysporum presentaron esporodoquios, sin embargo, los aislados de $F$. phyllophylum no mostraron esta estructura, a excepción del aislado G. Los macroconidios $F$. oxysporum mostraron una longitud que osciló entre 8,17-33,35 $\mu \mathrm{m}$, mientras que el ancho fluctuó entre 1,45-6,30 $\mu \mathrm{m}$, con formas semicurva y recta a ligeramente semicurva. Se observaron células apicales con forma curvada y ligeramente curvada, mientras que las células basales se mostraban ligeramente alargadas y alargadas en forma de pie, los macroconidios de esta especie presentaron 3 septos. Los macroconidios de $F$. phyllophylum registraron un largo que osciló entre 6,68-20,10 $\mu \mathrm{m}$, mientras que, el ancho fluctuó entre 1,42-4,67 $\mu \mathrm{m}$ con formas semicurva y recta a ligeramente semicurva, se observaron células apicales redondeadas, las células basales mostraron forma ligeramente redondeada, los macroconidios presentaron de 1-3 septos (Figura 5). 
SOSA-SÁNCHEZ et al:: Caracterización de Fusarium spp.

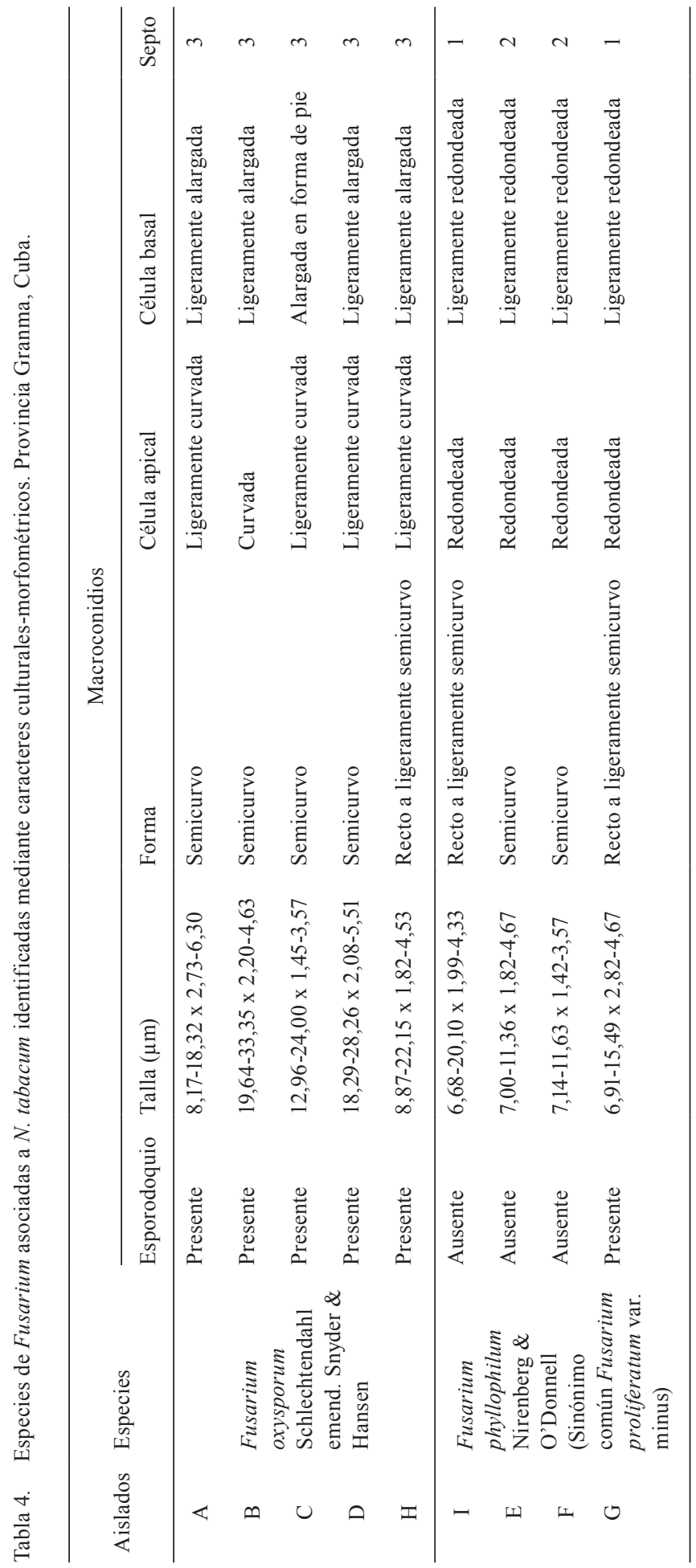

Agronomía Costarricense 46(1): 111-128. ISSN:0377-9424 / 2022 

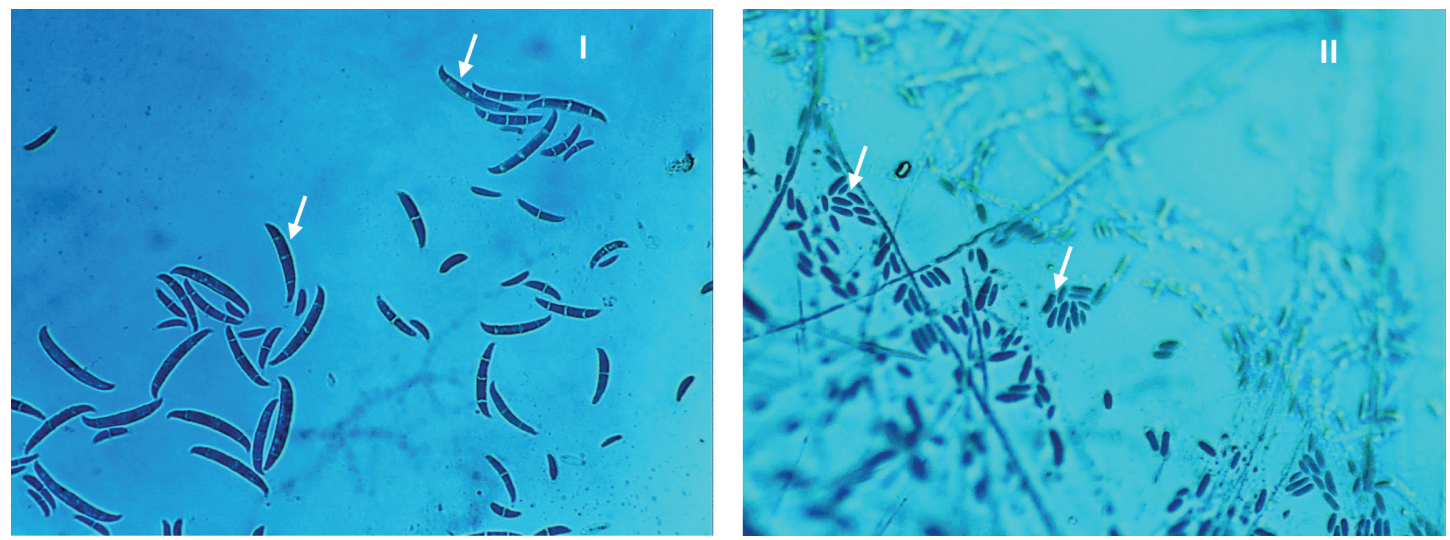

Figura 5. Forma de los macroconidios I ( F. oxysporum aislado B) y II (F. phyllophylum aislado G) crecidos en medio CLA, observados a $40 \mathrm{x}$.

Los microconidios de F. oxysporum y F. phyllophylum no presentaron septos. Estas estructuras en la especie $F$. oxysporum se mostraron de forma arriñonada, menos el aislado $\mathrm{C}$ que manifestó una apariencia oval, mientras que, en F. phyllophylum se exhibieron fusiformemente
(Tabla 5). Se observó la presencia de células conidiógenas monofiálides en todos los aislados de ambas especies. Las clamidosporas se observaron individualmente en los aislados de $F$. oxysporum. Ambas especies presentaron un micelio aéreo en falsas cabezas. 


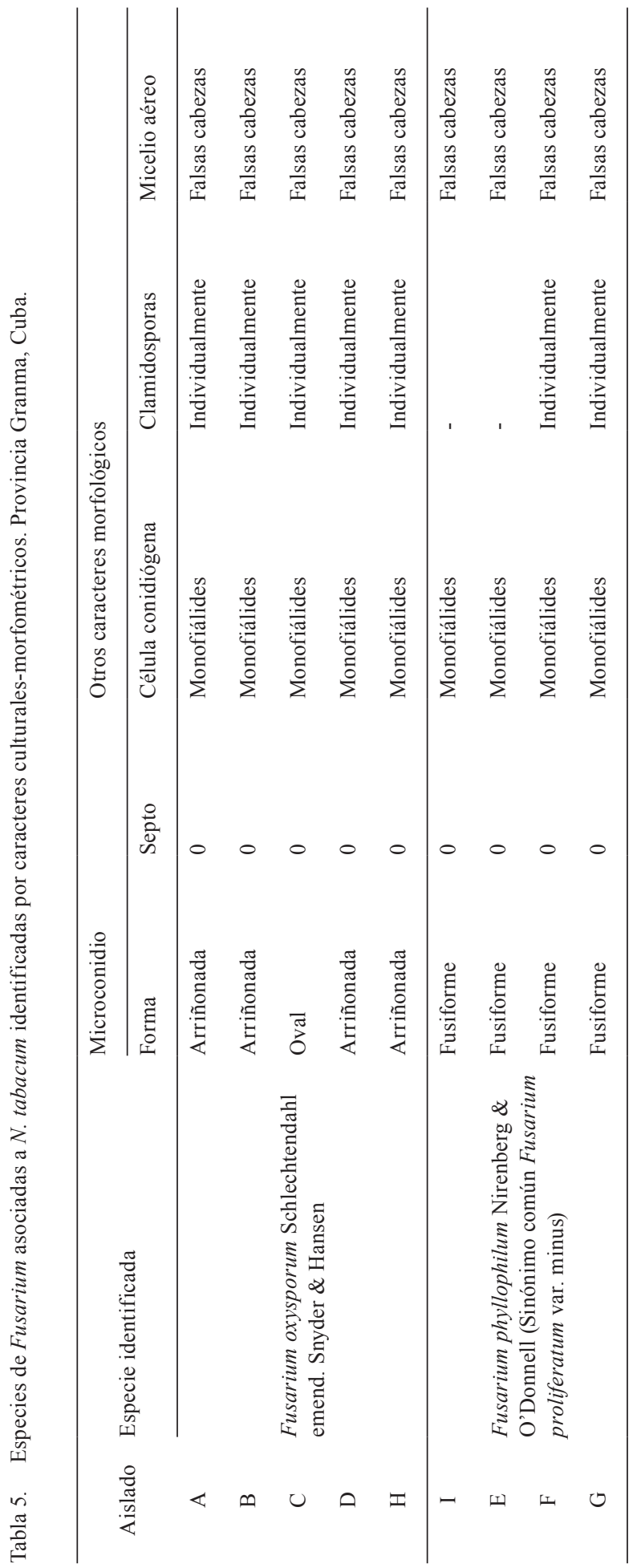

Agronomía Costarricense 46(1): 111-128. ISSN:0377-9424 / 2022 
Los resultados obtenidos en esta investigación poseen importancia para el programa nacional de selección y mejoramiento de variedades de N. tabacum tolerantes a Fusarium spp., muestran una alta especificación de $F$. oxysporum y $F$. phyllophylum como especies fitopatógenas asociadas a $N$. tabacum y evidencian los riesgos potenciales de proliferación del fitopatógeno en agroecosistemas tabacaleros.

\section{DISCUSIÓN}

En el medio PDA no se observó gran variabilidad cultural, lo cual pudo ser atribuido a la poca biodiversidad de especies presentes. Al respecto Tapia y Amaro (2014) y RenteríaMartínez et al. (2019) expresaron que aislados de Fusarium spp., crecidos en PDA mostraron una amplia diversidad de coloraciones, entre ellas café, rojo, violeta, naranja, gris y blanco. Las personas autoras constatan que dicha variabilidad se debió a la alta biodiversidad de especies presentes y observadas durante la investigación. Se conoce que la pigmentación del micelio puede deberse a la disponibilidad de nutrientes y al $\mathrm{pH}$ del medio de cultivo. Por su parte, Quilambaqui (2005) y Duarte et al. (2016) informaron que especies de Fusarium mostraron coloraciones del micelio violeta, púrpura, violáceo, amarillento, blanquecino, rojo ladrillo y rosa salmón en medio PDA a un pH de 6, tal variabilidad no fue observada en el presente estudio.

Los medios SNA, CLA y AN poseen baja concentración de nutrientes y de péptidos, lo cual pudo incidir sobre la pigmentación y el desarrollo de los aislados. Al respecto, Hernández Amasifuen et al. (2019) y Almaraz-Sánchez et al. (2018) informaron que medios pobres en nutrientes influyeron sobre la coloración y la formación de estructuras fúngicas de Fusarium spp., lo expuesto coincidió con el resultado obtenido en la presente investigación, donde se puso de manifiesto una escaza coloración del micelio fúngico.
La máxima velocidad media de crecimiento observada, pone de manifiesto una asimilación diferencial de los nutrientes por los aislados en cada medio de cultivo y se relaciona con la capacidad de colonización de este hongo en suelos y sustratos. Los resultados coinciden con lo informado por Dueñas et al. (2007), quienes expresaron que los aislados de Fusarium spp., obtenidos de Cicer arietinum mostraron un rápido crecimiento en medio PDA. Más recientemente Duarte et al. (2016) expusieron que aislados de Fusarium spp. procedentes de C. arietinum alcanzaron la mayor velocidad de crecimiento 0,63 mm.h ${ }^{-1}$ en medio Czapek Dox. En la presente investigación la mayor velocidad de crecimiento registrada por los aislados de Fusarium pudiera relacionarse con una rápida colonización de estos aislados en el suelo y sobre su hospedante vegetal.

La concentración de macroconidios constatada en esta investigación es mayor a los resultados obtenidos por Duarte et al. (2016) en especies de $F$. oxysporum aisladas de $C$. arietinum, los cuales registraron una esporulación entre $0,06-0,32 \times 10^{6}$ macroconidios. $\mathrm{mm}^{-2}$, mientras que en $F$. phyllophylum obtuvieron $0,34 \times 10^{6}$ macroconidios. $\mathrm{mm}^{-2}$ en medio PDA. En otros estudios, Lazarotto et al. (2014) y AlmarazSánchez et al. (2018) evidenciaron que en aislados de Fusarium spp., se alcanzó un rango de

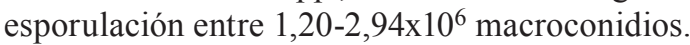
$\mathrm{mL}^{-1}$, dichos resultados fueron similares a los obtenidos en el presente estudio.

De acuerdo con los resultados obtenidos, se consideró que la variabilidad de los macroconidios en cuanto a su morfología, características de las células apicales y basales, su tamaño y la formación de septos, los reafirma como la principal estructura para la identificación de especies de Fusarium. Al respecto, Leyva-Mir et al. (2017) informaron que en una caracterización de especies de Fusarium obtenidas del trigo se desarrollaron macroconidios con una talla de $24-33 \times 2-2,3 \mu \mathrm{m}$ con 3 septos, célula apical curvada y basal ligeramente alargada, con micelio de coloración púrpura-violeta; mientras 
que, en aislados que obtuvieron una coloración blanca-amarillenta registraron un tamaño de $22-48 \times 2,5-4,2 \mu \mathrm{m}$. Por su parte, Duarte et al. (2016) registraron un tamaño de macroconidios de 11,04-39,22 $\mu \mathrm{m}$ de largo y 1,01-4,14 $\mu \mathrm{m}$ de ancho en $F$. oxysporum, lo cual coincidió con las características morfométricas de los aislados analizados en esta investigación.

Se considera que la variabilidad de los microconidios en cuanto a su forma, tamaño y presencia de septos posee una relación con el medio de cultivo donde crece y con la especie en cuestión. Al respecto, Leslie y Summerell (2008), Cardona-Piedrahíta y Castaño-Zapata (2019) informaron que los aislados de F. oxysporum mostraron microconidios en forma oval y arriñonados, células conidiógenas monofiálides, microconidios en falsas cabezas y clamidosporas individualmente, lo cual coincidió con lo observado en el presente estudio. En este mismo sentido, Duarte et al. (2016) informaron que los microconidios de F. phyllophylum procedentes de $C$. arietinum mostraron de 0-1 septos y una apariencia fusiforme, similar a lo descrito en esta investigación.

\section{CONCLUSIONES}

Se caracterizan eficazmente por el método combinado cultural-morfométrico 9 aislados de Fusarium spp., (5 de F. oxysporum y 4 de F. phyllophylum). La caracterización cultural evidenció una mayor variabilidad de la pigmentación en el medio PDA en comparación con los restantes medios, mientras que, la morfométrica demostró una diferenciación inter e intraespecífica en la formación de estructuras microscópicas, lo que verificó una talla de macroconidios que oscila entre $8,17-33,35 \times 1,45-6,30 \mu \mathrm{m}$ en $F$. oxysporum y de $6,68-20,10 x 1,42-4,67 \mu \mathrm{m}$ en $F$. phyllophylum. Lo expuesto, evidencia la selectividad de estas dos especies por $N$. tabacum y señala la necesidad de monitorear la fitopatogenecidad de este patógeno con el propósito de establecer su correspondiente manejo.

\section{LITERATURA CITADA}

Almaraz-Sánchez, A; Ayala-Escobar, V; TlatilpaSantamaría, IF; Nieto-Ángel, D. 2018. Fusarium sambucinum Fuckel agente causal de la pudrición de frutos de chile manzano (Capsicum pubescens) en México. Rev. Mex. Fitopatol 37(1):159-169. DOI: https://doi.org/10.18781/R.MEX.FIT.1810-2.

Barceló, AM; Mustelier, MR. 2019. Insectos nocivos asociados al cultivo del tabaco al sol (Nicotiana tabacum, L.) en una zona agroproductiva de la provincia de Las Tunas, Cuba. Rev. Dig. Med. Amb. "Ojeando la Agenda" 60(4):44-66.

Calero-Hurtado, A; Quintero-Rodríguez, E; Olivera-Viciedo, D; Peña-Calzada, K; Pérez-Díaz, Y. 2019. Influencia de dos bioestimulantes en el comportamiento agrícola del cultivo del tabaco (Nicotiana tabacum L.). Rev. Fac. Cienc. Méd 8(1):31-44.

Cardona-Piedrahíta, LF; Castaño-Zapata, J. 2019. Comparison of inoculation methods of Fusarium oxysporum f. sp. lycopersici Sacc.(Snyder \& Hansen), the causal agent of the vascular wilt of tomato. Rev. Acad. Colomb. Cienc. Exactas Fis. Nat 43(167):227-233. DOI: https://doi.org/10.18257/ raccefyn.854.

Castro López, W; Carrera Sánchez, K; Herrera Isla, FL; Cupull Santana, R. 2018. Identificación de aislados de Fusarium spp. asociados a Solanum quitoense Lam en Pastaza, Ecuador. Ctro. Agr 45(4):5-11.

Duarte, Y; Echevarría Hernández, A; Martínez Coca, B. 2016. Identificación y caracterización de aislamientos de Fusarium spp. presentes en garbanzo (Cicer arietinum L.) en Cuba. Rev. Protección Veg 31(3):173-183

Dueñas, G; Shagarodsky, T; Fresneda, J; Hernández, F; González, J. 2007. Caracterización del género de especies de Fusarium en el cultivo del garbanzo (Cicer arietimun) en las provincias ciudad Habana y La Habana. Rev. Protección Veg 11(32):63-66.

González, LM; Flores, FG; García, BM; Rivera, SG; Vázquez, FPG; Gallegos, JAA; Guerra, RR; Williamson, JS; Enciso, MC; Elos, MM. 2005. Especies de Fusarium presentes en raíces de frijol (Phaseolus vulgaris L.) con daños de pudrición, en cinco estados del centro de México. Rev. Mex. Fitopatol 23(1):1-7.

Hernández Amasifuen, AD; Pineda Lázaro, AJ; NoriegaCórdova, HW. 2019. Aislamiento e identificación de Fusarium oxysporum obtenidos de zonas productoras de" ají paprika" Capsicum annumm L.(Solanaceae) en el distrito de Barranca, Perú. Arnaldoa 26(2):689-698.

Lazarotto, M; Milanesi, PM; Muniz, MFB; Reiniger, LRS; Beltrame, R; Harakava, R; Blume, E. 2014. Morphological and molecular characterization of Fusarium spp pathogenic to pecan tree in Brazil. 
Genet. Mol. Res 13(4):9390-9402. DOI: https://doi. $\operatorname{org} / 10.4238 / 2014$.

Leslie, JF; Summerell, BA. 2008. The Fusarium laboratory manual. Lowa, USA, John Wiley \& Sons. 280 p.

Leyva-Mir, SG; Vega-Portillo, HE; Villaseñor-Mir, HE; Tlapal-Bolaños, B; Vargas-Hernández, M; Camacho-Tapia, M; Tovar-Pedraza, JM. 2017. Caracterización de especies de Fusarium causantes de pudrición de raíz del trigo en el Bajío, México. Chil. J. Agric. Anim. Sci 33(2):142-151.

Quilambaqui, MA. 2005. Aislamiento e identificación de especies de Fusarium spp asociadas al declinamiento del espárrago (Asparagus officinalis L.) en cinco municipios de Guanajuato, México. ESPOL Ciencia 18(1):135-140.

Rentería-Martínez, ME; Guerra-Camacho, M; Ochoa-Meza, A; Moreno-Salazar, F; Meza-Moller, AC; Guzmán-
Ortíz, JM. 2019. Description and comparison among morphotypes of Fusarium brachygibbosum, $F$. falciforme and $F$. oxysporum pathogenic to watermelon in Sonora, México. Rev. Mex. Fitopatol 37(1):16-34. DOI: https://doi.org/10.18781/R.MEX. FIT.1808-1.

Retana, K; Ramírez-Coché, JA; Castro, O; Blanco-Meneses, M. 2018. Caracterización morfológica y molecular de Fusarium oxysporum f. sp. apii asociado a la marchitez del apio en Costa Rica. Agronomía Costarricense 42(1):115-126.

Tapia, C; Amaro, J. 2014. Género Fusarium. Revista chilena de infectología 31(1):85-86.

Toledo, V; González, A; Martínez, J. 2016. Estabilidad de Trichoderma harzianum cepa A-53 en condiciones no controladas. Su influencia en la enfermedad pata prieta. CUBA TABACO 15(1):3-9. 